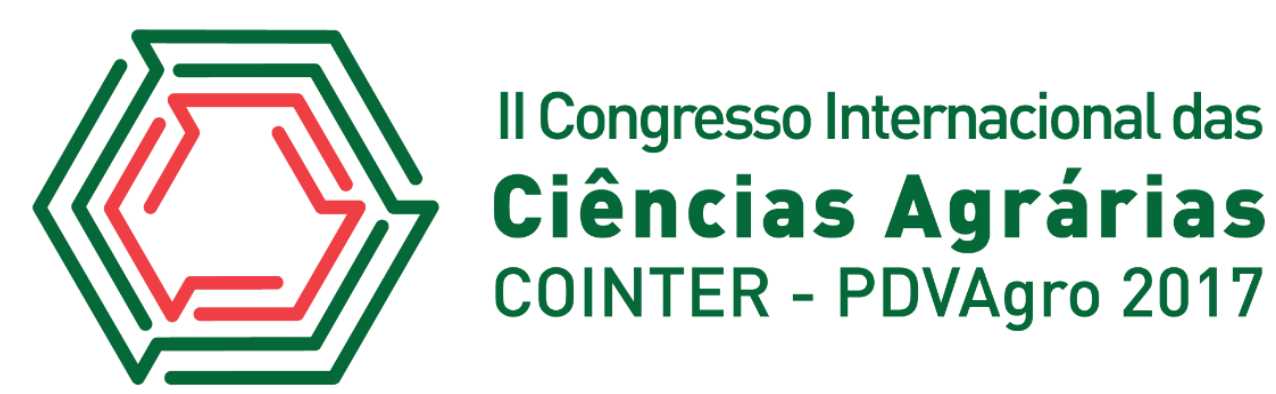

\title{
CRESCIMENTO VEGETATIVO DO FEIJÃO-CAUPI EM FUNÇÃO DO EMPREGO DE ADUBOS ORGÂNICOS E MINERAL
}

\author{
Apresentação: Pôster \\ Jeferson da Silva Zumba ${ }^{1}$; José Daniel da Silva Marques ${ }^{2}$; Charlley de Freitas Silva ${ }^{3}$; \\ Monalise de Melo Moraes ${ }^{4}$; Mácio Farias de Moura ${ }^{5}$
}

\section{Introdução}

O consumo de feijão-caupi é uma importante fonte de nutrientes para a população principalmente para a parte mais pobre. A cultura consegue boas produções mesmo em solos poucos férteis e por isso há um interesse em aumentar a produção utilizando fontes alternativas de adubação visando uma produtividade que expresse seu potencial. O emprego de fertilizantes como esterco bovino, biofertilizante e inoculante são benéficas tanto do ponto de vista econômico quanto ambiental. Portanto, é necessário que as pesquisas sejam intensificadas, juntamente com o manejo favorável ao desempenho da cultura.

\section{Fundamentação teórica}

Empregado na alimentação humana, o feijão-caupi (Vigna unguiculata L. Walp.) é a principal fonte de proteína de populações pobres no mundo, notadamente, em países da América latina e África (Almeida et al., 2010). É uma fonte de renda e alimento básico para população da Região Nordeste do Brasil que o consome sob as formas de grãos secos ou verdes (Oliveira et al., 2000). Apesar de ser uma cultura de grande relevância, ainda é considerada pouco produtiva, tendo seu potencial genético pouco explorado, com rendimentos médios de produtividade de grãos secos na faixa de 300 a $400 \mathrm{~kg} \mathrm{ha}^{-1}$ (Frota \& Pereira, 2000). O emprego de adubos orgânicos melhora as características físicas, químicas e biológicas do solo proporcionando aumento da produção das culturas. A adubação com fertilizantes orgânicos sólidos no solo pode

${ }^{1}$ Agronomia, Universidade Federal Rural de Pernambuco (UFRPE/UAG). Av. Bom Pastor S/N, Bairro: Boa Vista, CEP: 55.296-901, Garanhuns - PE. E-mail: jefersonszagro@gmail.com

${ }^{2}$ Agronomia, Universidade Federal Rural de Pernambuco (UFRPE/UAG). Av. Bom Pastor S/N, Bairro: Boa Vista, CEP: 55.296-901, Garanhuns - PE. E-mail: danielmarquesagro@ outlook.com

${ }^{3}$ Agronomia, Universidade Federal Rural de Pernambuco (UFRPE/UAG). Av. Bom Pastor S/N, Bairro: Boa Vista, CEP: 55.296-901, Garanhuns - PE. E-mail: charlleyfs@ hotmail.com

${ }_{4}^{4}$ Agronomia, Universidade Federal Rural de Pernambuco (UFRPE/UAG). Av. Bom Pastor S/N, Bairro: Boa Vista, CEP: 55.296-90, Garanhuns - PE. E-mail: danielmarques018@gmail.com

${ }^{5}$ Professor Doutor, Universidade Federal Rural de Pernambuco (UFRPE/UAG). Av. Bom Pastor S/N, Bairro: Boa Vista, CEP: 55.296-901, Garanhuns - PE. E-mail: maciof@yahoo.com.br 
ser complementada com o uso de biofertilizantes. Estes possuem em sua composição nutrientes que são disponibilizados com maior facilidade em relação a outros adubos orgânicos (Oliveira et al., 2014). A prática de inoculação de semente com bactérias fixadoras de nitrogênio é uma boa alternativa do ponto de vista econômico além de proporcionar ganhos na produtividade. O estudo teve como objetivo avaliar o efeito da aplicação do esterco bovino, biofertilizante e inoculação com bactérias fixadoras de nitrogênio e da adubação mineral no crescimento vegetativo do feijão-caupi.

\section{Material e métodos}

$\mathrm{O}$ experimento foi realizado na Fazenda Experimental pertencente à Universidade Federal Rural de Pernambuco/Unidade Acadêmica de Garanhuns (UFRPE/UAG) de novembro de 2015 a março de 2016, localizada na latitude $08^{\circ} 58^{\prime} 28^{\prime \prime} \mathrm{S}$ e longitude de $36^{\circ} 27^{\prime} 11^{\prime \prime} \mathrm{O}$, altitude de $736 \mathrm{~m}$. Antes da instalação do experimento, coletou-se solo para a realização da análise química, que ocorreu no laboratório de solos do Instituto Agronômico de Pernambuco (IPA). A análise química apresentou pH em água 5,59; $\mathrm{Al}^{+3}, 0,0 \mathrm{cmolc} \mathrm{dm}{ }^{-3} ; \mathrm{Ca}^{+2}, 2,75 \mathrm{cmolc} \mathrm{dm}^{-3} ; \mathrm{Mg}^{+2}, 0,75$ cmolc $\mathrm{dm}^{-3} ; \mathrm{P}, 2 \mathrm{mg} \mathrm{dm}^{-}{ }^{3}$; e K $\mathrm{K}^{+}, 0,21 \mathrm{mg} \mathrm{dm}^{-3}$.

O delineamento experimental foi em blocos ao acaso, constituído por nove tratamentos e três repetições. Os tratamentos foram: $\mathrm{T}$ - testemunha absoluta; $\mathrm{E}$ esterco bovino; B - biofertilizante; I - inoculante; EI - esterco bovino + inoculante; BI - biofertilizante + inoculante; EB - esterco bovino + biofertilizante; EBI - esterco bovino + biofertilizante + inoculante; AM - adubação mineral.

O esterco bovino foi distribuído de maneira uniforme, quinze dias antes da realização do semeio do feijão-caupi, numa dose equivalente $12 \mathrm{~m}^{3} \mathrm{ha}^{-1}$. Para a adubação mineral, foram aplicados $25 \mathrm{~kg} \mathrm{ha}^{-1}$ de $\mathrm{N}$ (sulfato de amônio), $60 \mathrm{~kg} \mathrm{ha}^{-1}$ de $\mathrm{P}_{2} \mathrm{O}_{5}$ (superfosfato simples) e $20 \mathrm{~kg} \mathrm{ha}^{-1}$ de $\mathrm{KCl}$ (cloreto de potássio). As adubações minerais e orgânicas foram realizadas conforme o manual de recomendação de adubação para o Estado de Pernambuco. Foram empregadas sementes de feijão-caupi da cultivar Miranda IPA 207. O semeio foi realizado em sulcos com espaçamento $0,8 \mathrm{~m}$ e densidade de 4 plantas por metro linear. Para a inoculação, foi empregada a estirpe de inoculante de Rhyzobium spp. do IPA (Instituto Agronômico de Pernambuco) na dose de $200 \mathrm{~g} / 7 \mathrm{~kg}$ de sementes. A inoculação consistiu em misturar as sementes de feijãocaupi com o inoculante, o qual foi previamente umedecido com a solução açucarada a $10 \%$. O biofertilizante líquido foi aplicado a uma quantidade de $10 \mathrm{~mL}$ por planta na 
concentração de $20 \%$, em aplicações semanais até a floração, a partir da qual foram feitas aplicações a cada quinze dias, até a realização da primeira colheita. No período compreendido entre a semeadura e a emergência das plântulas, o biofertilizante foi pulverizado via solo. Após emergência, as pulverizações eram direcionadas às plantas.

Para confecção do biofertilizante líquido, foram utilizados 40 litros de digesta bovina diluída em 160 litros de água no interior de uma bombona plástica com capacidade de 240 litros. À solução, foi adicionado MB-4 (um pó de rochas que contém diversos nutrientes como magnésio, ferro, fósforo, cálcio, enxofre, cobre, manganês, entres outros). A solução foi mantida sob fermentação aeróbica por 30 dias para ser utilizada como biofertilizante líquido. Para evitar problemas de deficiência hídrica, foi instalado um sistema de gotejamento e foi realizado uma capina aos 45 dias após a semeadura. Variáveis analisadas: Altura do caule, número de folhas por planta, biomassa seca da parte aérea. Os dados foram submetidos à análise de variância e as médias de tratamentos comparadas pelos testes de Dunnett a $5 \%$ de probabilidade. O software para a análise estatística empregado foi o SAEG 8.0.

\section{Resultados e discussões}

Nas Tabelas 1 e 2, encontram-se os resultados da altura do caule (ALTC), número de folhas por planta (NFP), biomassa seca da parte aérea (BMSA) de feijãocaupi cultivado com inoculante e adubos orgânicos e minerais.

$\mathrm{Na}$ tabela 1, observa-se que a altura do caule em plantas que foram adubadas com esterco bovino + biofertilizante (EB) e esterco bovino + biofertilizante + inoculante (EBI) alcançaram altura superior à que foi constatada em plantas cultivadas sem adubação (testemunha). Os demais adubos não influenciaram significativamente a referida variável, observando-se valores iguais estatisticamente aos que foram encontrados na testemunha (T). Certamente, a associação do esterco bovino com biofertilizante, bem como dos referidos adubos orgânicos com o inoculante, podem ter atuado sinergicamente para o crescimento do caule do feijão-caupi. De acordo com os resultados encontrados por Pereira et al. (2013), o comprimento do ramo principal do feijão Vigna pode ser influenciado por doses crescentes de esterco bovino, mas pode ter efeito contrário quando as dosagens são elevadas. Alves et al. (2009), trabalhando com feijão, verificaram que a concentração de biofertilizante de $120 \mathrm{~mL} \mathrm{~L}^{-1}$ incrementou $5,76 \%$ a altura das plantas em relação à testemunha (concentração $0 \mathrm{~mL} \mathrm{~L}^{-1}$ ). Ao utilizar a adubação mineral como referência (Tabela 2), observa-se que o maior crescimento em 
altura ocorreu onde ele foi aplicado. Esse resultado pode ser explicado, principalmente, pela presença do nitrogênio prontamente disponível do fertilizante mineral, pois ele é o principal nutriente atuante no crescimento vegetal.

Tabela 1: Altura do caule (ALTC), número de folhas por planta (NFP) e biomassa seca da parte aérea (BMSA) de feijão-caupi submetido à adubação orgânica, mineral e inoculante em Garanhuns-PE de nov/2015 a mar/2016. Fonte: Própria.

\begin{tabular}{lccc}
\hline TRAT & ALTC $(\mathbf{c m})$ & NFP & BMSA $^{\left(\mathbf{k g ~ h a}^{-\mathbf{1}}\right)}$ \\
\hline T & 18,80 & 8,27 & 510,84 \\
\hline E & $23,00^{\mathrm{ns}}$ & $13,49^{*}$ & $579,41^{\mathrm{ns}}$ \\
$\mathrm{B}$ & $20,58^{\mathrm{ns}}$ & $11,33^{\mathrm{ns}}$ & $591,56^{\mathrm{ns}}$ \\
$\mathrm{I}$ & $17,77^{\mathrm{ns}}$ & $9,73^{\mathrm{ns}}$ & $425,09^{\mathrm{ns}}$ \\
EI & $21,68^{\mathrm{ns}}$ & $11,47^{\mathrm{ns}}$ & $619,01^{\mathrm{ns}}$ \\
BI & $21,31^{\mathrm{ns}}$ & $10,73^{\mathrm{ns}}$ & $627,23^{\mathrm{ns}}$ \\
EB & $25,07^{*}$ & $13,10^{*}$ & $775,17^{*}$ \\
EBI & $25,32^{*}$ & $13,33^{*}$ & $730,46^{*}$ \\
\hline Dms & 4,58 & 4,51 & 170,1 \\
\hline CV & 8,01 & 14,17 & 9,12 \\
\hline
\end{tabular}

ns e *, não significativo e significativo, respectivamente, a 5\% de probabilidade pelo teste de Dunnett. TRAT-tratamentos: T - Testemunha; E - Esterco; B - Biofertilizante; I - Inoculante; EI - Esterco + inoculante; BI - Biofertilizante + inoculante; EB - Esterco + biofertilizante; EBI - Esterco + biofertilizante + inoculante. dms = diferença mínima significativa. CV - coeficiente de variaçao.

Tabela 2: Altura do caule (ALTC), número de folhas por planta (NFP) e biomassa seca da parte aérea (BMSA) de feijão-caupi submetido à adubação orgânica, mineral e inoculante em Garanhuns-PE de nov/2015 a mar/2016. Fonte: Própria.

\begin{tabular}{lccc}
\hline TRAT & ALTC $(\mathbf{c m})$ & NFP & BMSA $\left(\mathbf{k g ~ h a}^{-1}\right)$ \\
\hline AM & 38,13 & 26,57 & 2075,22 \\
\hline E & $23,00^{*}$ & $13,49^{*}$ & $579,41^{*}$ \\
B & $20,58^{*}$ & $11,33^{*}$ & $591,56^{*}$ \\
I & $17,77^{*}$ & $9,73^{*}$ & $425,09^{*}$ \\
EI & $21,68^{*}$ & $11,47^{*}$ & $619,01^{*}$ \\
BI & $21,31^{*}$ & $10,73^{*}$ & $627,23^{*}$ \\
EB & $25,07^{*}$ & $13,10^{*}$ & $775,17^{*}$ \\
EBI & $25,32^{*}$ & $13,33^{*}$ & $730,46^{*}$ \\
\hline Dms & 4,58 & 4,51 & 170,1 \\
\hline CV & 8,01 & 14,17 & 9,12 \\
\hline
\end{tabular}

ns e *, não significativo e significativo, respectivamente, a $5 \%$ de probabilidade pelo teste de Dunnett. TRAT-tratamentos: AM - Adubação mineral; E - Esterco; B - Biofertilizante; I - Inoculante; EI - Esterco + inoculante; BI - Biofertilizante + inoculante; EB - Esterco + biofertilizante; EBI - Esterco + biofertilizante + inoculante. Dms - diferença mínima significativa. CV - coeficiente de variação.

Quanto as variáveis número de folhas por planta (NFP) e biomassa seca da parte aérea, observa-se que para a primeira, houve superioridade quando as plantas foram adubadas com esterco bovino (E), esterco bovino + biofertilizante (EB) e esterco bovino + biofertilizante + inoculante $(\mathrm{EBI})$, diferindo estatisticamente da quantidade de folhas verificadas em plantas sem adubação (testemunha). Já em relação a biomassa seca da parte aérea, a referida diferença ocorreu quando do emprego dois últimos adubos 
citados anteriormente. Porém, conforme os resultados apresentados na Tabela 2, quando a adubação mineral foi utilizada como tratamento referência na comparação com os demais, constatou-se superioridade do número de folhas e da biomassa seca da parte aérea de plantas que receberam a adubação mineral. Possivelmente, em função do nitrogênio prontamente disponível no fertilizante mineral e pela alta relação deste com fase vegetativa do feijoeiro.

\section{Conclusão}

O esterco bovino e sua associação com biofertilizante e inoculante pode proporcionar um desempenho no comportamento vegetativo de feijão-caupi quando ausência de fertilizante mineral.

\section{Referências}

ALMEIDA, A.L.G.; ALCÂNTARA, R.M.C.M.; NÓBREGA, R.S.A.; NÓBREGA, J.C.A.; LEITE, L.F.C.; SILVA, J.A.L. Produtividade do feijão-caupi cv BR 17 Gurguéia inoculado com bactérias diazotróficas simbióticas no Piauí. Revista Brasileira de Ciências Agrárias, p.364-369, 2010.

ALVES, J.M.A.; ARAÚJO, N.P.; UCHÔA, S.C.P.; ALBUQUERQUE, J.A.A.; SILVA, A.J.; RODRIGUES, G.S.; SILVA, D.C.O. Avaliação agroeconômica da produção de cultivares de feijão-caupi em consórcio com cultivares de mandioca no cerrado de Roraima.RevistaAgro@mbiente On-line, Boa Vista, v.3, n.1, p.15-30, 2009.

FROTA, A. B.; PEREIRA, P. R. Caracterização da produção de feijão-caupi na região Meio-Norte do Brasil. In: CARDOSO, M. J. (Org.) A cultura do feijão-caupi no MeioNorte do Brasil. Teresina: Embrapa Meio Norte, 2000. p. 9-25. (Embrapa Meio Norte. Circular Técnica, 28).

OLIVEIRA, A. P.; ALVES. E. U.; BRUNO, R. L. A.; BRUNO, G. B. Produção e qualidade de sementes de feijão-caupi (Vigna unguiculata (1.) Walp.) Cultivado com esterco bovino e adubo mineral. Revista Brasileira de Sementes, v. 22, n. 2, p.102-108, 2000.

OLIVEIRA, A.P.; SILVA, O. P. R.; BANDEIRA, N.V.S.; SILVA, D.F.; SILVA, J.A.; PINHEIRO, S.M.G. Rendimento de maxixe em solo arenoso em função de doses de esterco bovino e biofertilizante. Revista Brasileira de Engenharia Agrícola e Ambiental, v.18, p.1130-1135, 2014.

PEREIRA, R.F.; LIMA, A.S.; MAIA FILHO, F.C.F.; CAVALCANTE, S.N.; SANTOS, J.G.R.; ANDRADE, R. Produção de feijão vigna sob adubação orgânica em ambiente semiárido. Agropecuária Científica no Semi-Árido, Patos, v.9, n.2, p.27-32, 2013. 